\title{
Experimental and numerical investigation of flow field and heat transfer from electronic components in a rectangular channel with an impinging jet
}

\author{
Tamer Calisir ${ }^{1, a}$, M. Fevzi Koseoglu², Mustafa Kilic ${ }^{3}$ and Senol Baskaya ${ }^{1}$ \\ ${ }^{1}$ Gazi University, Mechanical Engineering Department, 06570 Ankara, Turkey \\ 2 Pamukkale University, Mechanical Engineering Department, 20020 Denizli, Turkey \\ ${ }^{3}$ Adana Science and Technology University, Mechanical Engineering Department, 01000 Adana, Turkey
}

\begin{abstract}
Thermal control of electronic components is a continuously emerging problem as power loads keep increasing. The present study is mainly focused on experimental and numerical investigation of impinging jet cooling of $18(3 \times 6$ array) flash mounted electronic components under a constant heat flux condition inside a rectangular channel in which air, following impingement, is forced to exit in a single direction along the channel formed by the jet orifice plate and impingement plate. Copper blocks represent heat dissipating electronic components. Inlet flow velocities to the channel were measured by using a Laser Doppler Anemometer (LDA) system. Flow field observations were performed using a Particle Image Velocimetry (PIV) and thermocouples were used for temperature measurements. Experiments and simulations were conducted for $\mathrm{Re}=4000-8000$ at fixed value of $\mathrm{H}=10 \times \mathrm{D}_{\mathrm{h}}$. Flow field results were presented and heat transfer results were interpreted using the flow measurement observations. Numerical results were validated with experimental data and it was observed that the results are in agreement with the experiments.
\end{abstract}

\section{Introduction}

Impingement heat transfer is considered as an attractive heat transfer enhancement technique. Among all convection heat transfer enhancement methods, it provides significantly higher local heat transfer coefficients. Thermal control of electronic components is a continuously emerging problem as power loads keep increasing. It is supposed that the power dissipation of future electronic components will reach $45 \mathrm{~W} \mathrm{~cm}^{-2}$ or greater, and the electronic industry is seeking more effective ways to remove localized heat loads [1]. The design of a thermal control system considers two main demands; the heat flux to be dissipated and the permitted temperature rise above the local ambient conditions. For heat fluxes below $0.05 \mathrm{~W} \mathrm{~cm}$-2 with an allowable temperature difference of about $60{ }^{\circ} \mathrm{C}$, radiation and natural convection are usually sufficient means of heat dissipation. For fluxes of $1-2 \mathrm{~W} \mathrm{~cm}^{-2}$, it can be achieved by forced convection. For higher heat fluxes, impinging jets provide a potential solution [1]. In recent years, various industries have used the impingement cooling technique as an efficient approach to dissipate heat for protecting components that experience either high heat flux or high temperatures.

Besides cooling of electronic components, impinging jets are also used in cooling of gas turbine blades, glass tempering, and heat processing of metals.
For the enhancement of heat transfer, several active and passive techniques are known. For example; passive techniques like casting artificial roughness, placing obstacles on the solid boundary or directing fluid to target plate can substantially increase the wall heat transfer coefficient. Such boundary modifications can generate vortices, which increase mixing, reducing the thickness of the thermal boundary layer, and thereby enhance heat transfer. Active techniques which require external power input are also widely used.

Many experimental investigations on impinging jets and their applications were performed and can be found in the literature. Effects of different nozzle geometries and multiple jet flows on heat transfer were investigated experimentally by Nada [2], and it was reported that higher heat transfer rate can be achieved by using more slot jets. An increased heat transfer was obtained by using jet flow with channel flow in the study by Cheng-Geng and Jie-Min [3] and Yan et al. [4]. Comparisons of free jets with confined jets have been made by Choo and Kim [5]. Caliskan [6, 7] conducted an experimental study to investigate heat transfer and flow characteristics under impingement of a multiple circular jet array with perforated rib surfaces and solid rib surfaces. Caliskan and Baskaya [8] investigated the heat transfer over a surface with $\mathrm{V}$-shaped ribs and convergent-divergent shaped ribs by a circular impinging jet array using thermal infrared camera. Koseoglu and Baskaya [9]

${ }^{a}$ Corresponding author: tamercalisir@gazi.edu.tr 
investigated experimentally the effect of jet inlet geometry and aspect ratio on local and average heat transfer characteristics of totally nine confined impinging jets using thermocromic liquid crystals. Geers et al. [10] reported in their paper on measurements of the velocity field and turbulence fluctuations in a hexagonal array of circular jets, impinging normally on a plane wall using particle image velocimetry (PIV). In another experimental study, Geers et al. [11] reported results of heat transfer measurements in hexagonal and in-line arrays of impinging jets using liquid crystal thermography to determine the temperature distribution on the flat impingement plate. Effects of jet flows on heat transfer and flow characteristics were investigated numerically by Jia et al. [12]. They reported that turbulence intensity and velocity profile at jet entrance have important effects on heat transfer. Jet flow and channel flow are used together in the study by Rundstrom and Moshfegh [13]. Wang and Mujumdar [14] analysed five versions of low Reynolds number $\mathrm{k}-\varepsilon$ models for the prediction of heat transfer under a two-dimensional turbulent slot jet by comparison with available experimental data. Bredberg and Davidson [15] presented a new near-wall treatment for low-Reynolds number turbulence models that maintain accuracy in coarse mesh predictions. Koutsou et al. [16] studied a model flow geometry consisting of a plane-channel, where a regular array of cylinders is inserted, acting as turbulence promoters.

The present study is mainly focused on experimental and numerical investigation of heat transfer and flow from a group of electronic components, inside a rectangular channel, by using a single jet flow. The local Nusselt numbers were calculated for different Reynolds numbers. The numerical study was performed and validated with experimental results.

\section{Experimental setup}

The present study is mainly focused on an experimental investigation of cooling of $18(3 \times 6$ array $)$ electronic components, inside a rectangular channel, by using a single jet flow. A schematic of the experimental facility which consists of a PIV system, a frequency control unit, a fan, a wind tunnel, a computerized data acquisition system, a power unit and a test section is shown in Figure 1. The power unit includes a variac, voltage regulator and a wattmeter. The test section is composed a jet plate, target plate and side walls.

The channel is made of acrylic glass and its geometry is shown in Figure 2. Experiments were performed using a $5.5 \times 50 \mathrm{~mm}$ rectangular nozzle. Hydraulic diameter of the slot is $9.9 \mathrm{~mm}$. To represent electronic components, copper plates of $10 \times 10 \times 3 \mathrm{~mm}$ were used. Resistance wire was used to provide required heat flux $\left(1000 \mathrm{~W} \mathrm{~m}^{-2}\right)$ to copper plates. The total power supplied was monitored using digital multimeters for the control of voltage and current. A heater was placed at the back of the copper blocks which provides a uniform heat flux. Copper blocks and heater were imbedded inside thick insulation. Three layers of different materials were used to insulate the back side of the target plate. The first layer was teflon with a thickness of $20 \mathrm{~mm}\left(\mathrm{k}=0.25 \mathrm{~W} \mathrm{~m}^{-1} \mathrm{~K}^{-1}\right)$, the second layer was fiber glass with a thickness of $20 \mathrm{~mm}(\mathrm{k}$ $\left.=0.04 \mathrm{~W} \mathrm{~m}^{-1} \mathrm{~K}^{-1}\right)$ and the third one was polystyrene foam board with a thickness of $250 \mathrm{~mm}\left(\mathrm{k}=0.032 \mathrm{~W} \mathrm{~m}^{-1} \mathrm{~K}^{-1}\right)$.

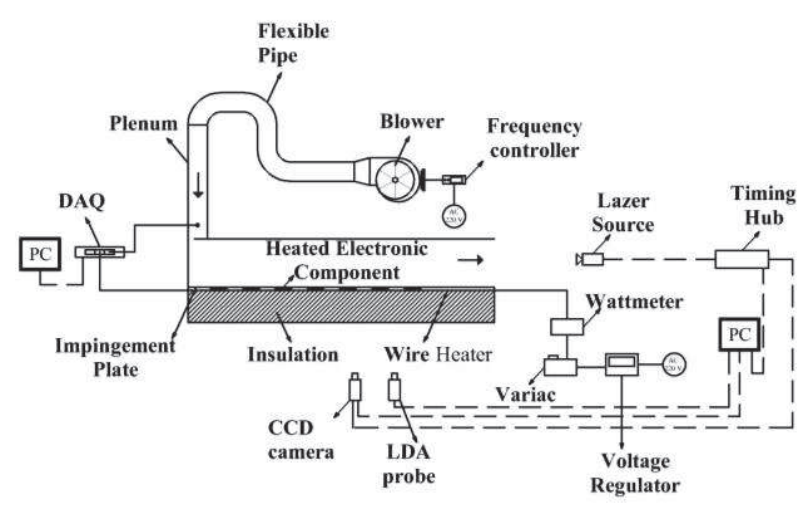

Figure 1. Experimental Setup

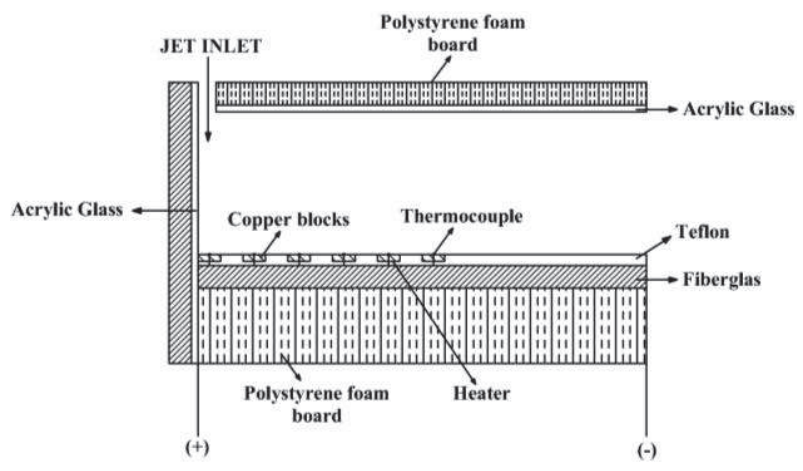

Figure 2. Details of Test Section

Temperatures at the centers of copper blocks were measured using calibrated T-type thermocouples inserted through $2 \mathrm{~mm}$ holes inside the thickness of the blocks. Conventional temperature measurements of the plate surface were used to evaluate the local heat transfer coefficients. Inlet jet velocity measurements were performed using Dantec 2-D Laser-Doppler Anemometry (LDA) system. The system operating in backscatter mode is used in conjunction with a $300 \mathrm{~mW}$ Argon Ion laser. Flow field measurements were performed along the rectangular channel using a Dantec 2-D digital PIV system. The system consist of a CCD camera with a resolution of $1600 \times 1200$ pixel, a double cavity laser source with $120 \mathrm{~mJ}$ power, laser control unit, timing hub, laser cooling case, fog generator, traverse system and a computer with Dynamic Studio software.

\section{Data reduction, mathematical formulation and numerical model}

The focus of the present investigation is to examine effects of different Re numbers on local Nusselt numbers. Experiments were conducted for different Re numbers $(\operatorname{Re}=4000,6000$ and 8000).

Jet velocity was used to calculate the jet inlet Reynolds number by the equation given below; 


$$
R e=\rho V_{j} D_{h} / \mu
$$

Where $\mathrm{V}_{\mathrm{j}}$ is the jet inlet velocity, $\mathrm{m} \mathrm{s}^{-1}$, measured by the LDA system, $D_{h}$ is the hydraulic diameter of the nozzle, $\mathrm{m}, \mu$ is the dynamic viscosity, $\mathrm{Pa} \mathrm{s}$, and $\rho$ is the density of air at the inlet air temperature, $\mathrm{kg} \mathrm{m}^{-3}$.

The heat removal takes place by the three modes of heat transfer: convection, conduction and radiation. Corrections were made for these losses and the convective heat transfer was adjusted accordingly;

$$
Q_{\text {conv }}=Q_{\text {tot }}-Q_{\text {cond }}-Q_{\text {rad }}
$$

Where $Q_{\text {tot }}$ is the total heat input calculated from;

$$
Q_{t o t}=V^{2} / R
$$

Where $V$ is the voltage of power supply and $R$ is the resistance of the wire, where a wire with a resistance of $45 \Omega \mathrm{m}^{-1}$ was used.

Conjugate heat transfer was solved in the numerical model. The heat generated by the heater under the copper plate is conducted through the thickness of the target plate to the upper surface, and eventually convected by the impinging air jet.

Heat transfer with conduction from the heater to the upper surface of the copper blocks has been calculated from the equation given below;

$$
Q_{\text {cond }}=k_{c} \cdot A_{c}\left(T_{\text {bot }}-T_{\text {top }}\right) / L_{c}
$$

Where $k_{c}, A_{c}$ and $L_{c}$ are the thermal conductivity, W $\mathrm{m}^{-1} \mathrm{~K}^{-1}$, the surface area, $\mathrm{m}^{2}$, and thickness of copper blocks, $\mathrm{m}$, respectively. The conduction heat losses through the insulations were monitored by measuring the temperatures of the insulation surfaces. Heat loss from three channel walls and the bottom of the channel was calculated to be less than $2 \%$ of the total heat input. Conduction losses have been calculated from the equation given below;

$$
Q_{\text {cond }}=k_{\text {ins }} . A_{\text {ins }}\left(T_{\text {inside }}-T_{\text {outside }}\right) / L_{\text {ins }}
$$

Where $k_{\text {ins }}, A_{\text {ins }}$ and $L_{\text {ins }}$ are the thermal conductivity, $\mathrm{W} \mathrm{m} \mathrm{m}^{-1} \mathrm{~K}^{-1}$, the surface area, $\mathrm{m}^{2}$, and thickness of copper blocks, $\mathrm{m}$, the surface area and thickness of insulation, respectively. An estimation of the heat loss by radiation was also calculated, and its maximum was less than $1 \%$ of the total heat input. Radiation losses have been calculated from the equation given below;

$$
Q_{\text {rad }}=\varepsilon \cdot \sigma \cdot A \cdot F \cdot\left(T_{s}^{4}-T_{b u l k}{ }^{4}\right)
$$

Where $\varepsilon$ is the emissivity of the copper surface $(\varepsilon=0.3)$, $\sigma$ is the Stefan-Boltzman constant, $5.67 \times 10^{-8} \mathrm{~W} \mathrm{~m}^{-2} \mathrm{~K}^{-4}, T_{s}$ is the surface temperature and $T_{b u l k}$ is the bulk temperature, $\mathrm{K}$. Outlet and bulk temperatures have been calculated from the equations given below;

$$
T_{\text {outlet }}=\left(q^{\prime \prime} / m c_{p}\right)+T_{\text {inlet }}
$$

$$
T_{\text {bulk }}=\left(T_{\text {inlet }}+T_{\text {outlet }}\right) / 2
$$

Nusselt numbers were calculated by using the equation given below;

$$
N u=Q_{\text {conv }} D_{h} /\left(T_{s}-T_{\text {bulk }}\right) k_{\text {air }} A_{c}
$$

Where $D_{h}$ is the hydraulic diameter of the nozzle, $\mathrm{m}$, $k_{\text {air }}$ is the thermal conductivity of air, $T_{s}$ is the surface temperature and $T_{\text {bulk }}$ is the bulk temperature of the copper blocks.

\subsection{Problem description}

In this section, the numerical description of the problem under investigation is presented. Problem description, mathematical formulation, solution technique, boundary conditions and validation of the numerical model is described.

Lam-Bramhorst low Re k- $\varepsilon$ turbulence model was used for this numerical analysis. CFD simulation domain and the used mesh structure are shown in Figure 3 and Figure 4, respectively.

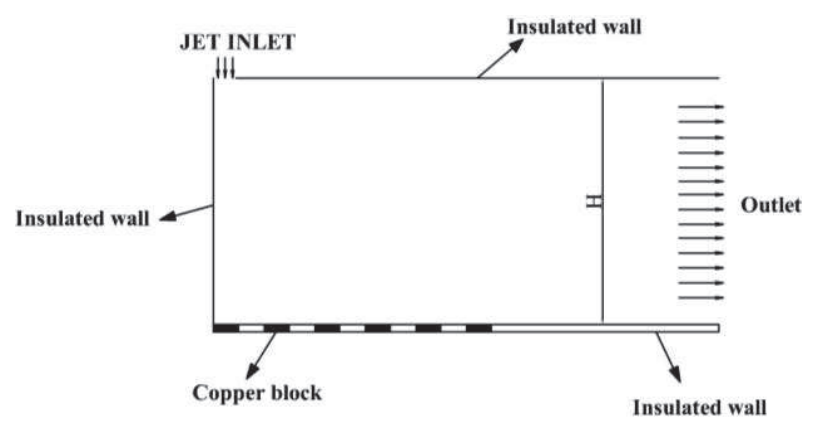

(a) Computational Domain

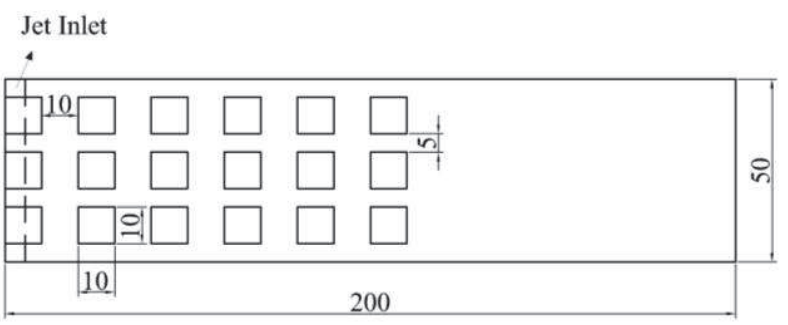

(b) Copper block heater locations

Figure 3. Details of the CFD simulation domain

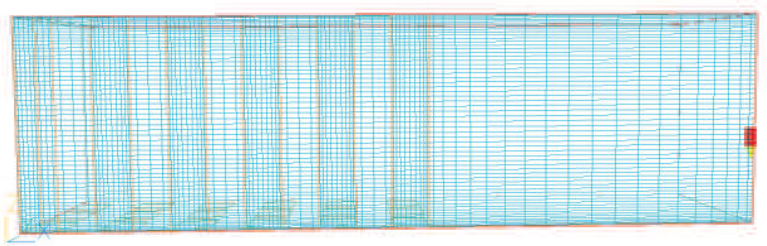

Figure 4. Mesh structure 
The implemented boundary conditions are shown on Figure 3 (a). In this study $\mathrm{H}=10 \times \mathrm{D}_{\mathrm{h}}$ and $\mathrm{L}=10 \mathrm{~mm}$ were used.

\subsection{Governing equations}

In this study, a three dimensional, steady, incompressible flow was modeled. Continuity, turbulent momentum and turbulent energy equations were solved under appropriate boundary conditions using PHOENICS CFD code. During the simulation radiation and natural convection effects were negligible. Electronic components have constant heat flux and all walls and bottom surfaces were insulated. The jet inlet temperature was assumed as $T_{j}=$ $20{ }^{\circ} \mathrm{C}$.

The continuity, Reynolds averaged momentum and time averaged energy equations governing 3-dimensional steady, flow of air with constant properties used for turbulent solutions can be written in the Cartesian coordinate system as follows:

Continuity equation:

$$
\partial \mathbf{U}_{\mathbf{i}} / \partial \mathbf{x}_{\mathbf{i}}=0
$$

Momentum equation:

$$
\begin{aligned}
& \rho \mathbf{U}_{\mathbf{i}} \frac{\partial \mathbf{U}_{\mathbf{j}}}{\partial \mathbf{x}_{\mathbf{i}}}=-\frac{\partial \mathbf{p}}{\partial \mathbf{x}_{\mathbf{j}}}+ \\
& \frac{\partial}{\partial \mathbf{x}_{\mathbf{i}}}\left[\mu\left(\frac{\partial \mathbf{U}_{\mathbf{i}}}{\partial \mathbf{x}_{\mathbf{j}}}+\frac{\partial \mathbf{U}_{\mathbf{j}}}{\partial \mathbf{x}_{\mathbf{i}}}\right)-\rho \overline{\mathbf{u}_{\mathbf{i}}^{\prime} \mathbf{u}_{\mathbf{j}}^{\prime}}\right]
\end{aligned}
$$

Energy equation:

$$
\rho c_{p} U_{i} \frac{\partial T}{\partial x_{i}}=\frac{\partial}{\partial x_{i}}\left[k \frac{\partial T}{\partial x_{i}}-\rho c_{p} \overline{u_{i}^{\prime} T^{\prime}}\right]
$$

Where $\rho, \mathbf{U}_{\mathbf{i}}, P, \mu, u_{i}^{\prime}, c_{p}, k, T, T^{\prime}$ are density, velocity, pressure, dynamic viscosity, turbulent velocity, specific heat, turbulent kinetic energy, temperature and turbulent temperature.

The transport equations of the $\mathrm{k}-\varepsilon$ model are modified to consider the low Reynolds number effects. Low Reynolds number $\mathrm{k}-\varepsilon$ model is obtained by multiplying the empirical coefficients $C_{\mu}, C_{1 \varepsilon}, C_{2 \varepsilon}$ of the standard model with damping functions. For this purpose, the Lam-Bramhorst low Reynolds number $\mathrm{k}-\varepsilon$ model was employed. The transport equations of the model are as follows:

$$
\begin{aligned}
\rho \mathbf{U}_{\mathbf{i}} \frac{\partial \mathbf{k}}{\partial \mathbf{x}_{\mathbf{i}}} & =\frac{\partial}{\partial \mathbf{x}_{\mathbf{i}}}\left[\left(\mu+\frac{\mu_{\mathbf{t}}}{\sigma_{\mathbf{k}}}\right) \frac{\partial \mathbf{k}}{\partial \mathbf{x}_{\mathbf{i}}}\right] \\
& +\mu_{\mathbf{t}}\left(\frac{\partial \mathbf{U}_{\mathbf{i}}}{\partial \mathbf{x}_{\mathbf{j}}}+\frac{\partial \mathbf{U}_{\mathbf{j}}}{\partial \mathbf{x}_{\mathbf{i}}}\right) \frac{\partial \mathbf{U}_{\mathbf{i}}}{\partial \mathbf{x}_{\mathbf{j}}}-\rho \varepsilon
\end{aligned}
$$

$$
\begin{aligned}
& \rho \mathbf{U}_{\mathbf{i}} \frac{\partial \varepsilon}{\partial \mathbf{x}_{\mathbf{i}}}=\frac{\partial}{\partial \mathbf{x}_{\mathbf{i}}}\left[\left(\mu+\frac{\mu_{\mathbf{t}}}{\sigma_{\varepsilon}}\right) \frac{\partial \varepsilon}{\partial \mathbf{x}_{\mathbf{i}}}\right] \\
& +\mathbf{f}_{1} \mathbf{C}_{1} \mu_{\mathbf{t}} \frac{\varepsilon}{\mathbf{k}}\left(\frac{\partial \mathbf{U}_{\mathbf{i}}}{\partial \mathbf{x}_{\mathbf{j}}}+\frac{\partial \mathbf{U}_{\mathbf{j}}}{\partial \mathbf{x}_{\mathbf{i}}}\right) \frac{\partial \mathbf{U}_{\mathbf{i}}}{\partial \mathbf{x}_{\mathbf{j}}}-\mathbf{f}_{2} \mathbf{C}_{2} \rho \frac{\varepsilon^{2}}{\mathbf{k}}
\end{aligned}
$$

The turbulent kinetic viscosity is expressed as:

$$
\mu_{t}=f_{\mu} C_{\mu} \rho\left(k^{2} / \varepsilon\right)
$$

The damping functions in the standard model are unity. $C_{\mu}, C_{1 \varepsilon}, C_{2 \varepsilon}$ are empirical constants of the k- $\varepsilon$ model and $\sigma_{k}$ and $\sigma_{\varepsilon}$ are turbulent Prandtl number for $\mathrm{k}$ and $\varepsilon$, respectively. The values of the constants are given below.

$$
\begin{gathered}
\sigma_{k}=1.00 ; \quad \sigma_{\varepsilon}=1.314 ; \quad C_{1}=1.44 \\
C_{2}=1.92 ; \quad C_{\mu}=0.09
\end{gathered}
$$

The damping functions of the Lam-Bramhorst low Reynolds number $\mathrm{k}-\varepsilon$ model are presented in the equations below.

$$
\begin{gathered}
f_{\mu}=\left[1-\exp \left(-0.0165 \operatorname{Re}_{z}\right)\right]^{2}\left(1+20.5 / R e_{t}\right) \\
f_{1}=\left(1+0.05 / f_{\mu}\right)^{3} \\
f_{2}=1-\exp \left(-\operatorname{Re}_{t}^{2}\right)
\end{gathered}
$$

Where

$$
\begin{aligned}
& R e_{t}=\rho k^{2} / \mu \varepsilon \\
& \operatorname{Re}_{z}=\rho k^{1 / 2} z / \mu
\end{aligned}
$$

Constant wall heat flux was applied to the copper blocks. Flow and heat transfer was modelled for steadystate conditions. Radiation effects were not considered.

All the boundary conditions used in the study are summarized in Table 1. As can be seen from the table, the boundary conditions for $\mathrm{k}$ and $\varepsilon$ are implemented according to the low Reynolds number turbulence model with wall damping functions. Velocities at the walls were taken as zero due to the no-slip condition. Constant surface heat flux $\left(q^{\prime \prime}\right)$ was applied to the impingement plate. The constant surface heat flux was taken as 1000 $\mathrm{W} \mathrm{m}^{-2}$. Contrary to the wall boundary conditions, the same boundary conditions for $\mathrm{k}$ and $\varepsilon$ can be applied to the outlet for the low Reynolds turbulence model as well as the standard model. It was accepted that the outlet is to the atmosphere. Solutions were obtained for sweep and grid independency checks. The optimum sweep number and mesh number in the $\mathrm{x}-\mathrm{y}-\mathrm{z}$ planes were selected as 7000 and $150-50-60$, respectively.

Numerical results were validated with experimental results and it was seen that the CFD results are in agreement with the experimental measurements [17]. 
Table 1. Boundary Conditions

\begin{tabular}{|c|c|c|c|c|c|c|}
\hline & $\mathbf{U}$ & $\mathbf{V}$ & $\mathbf{W}$ & $\mathbf{T}$ & $\mathbf{k}$ & $\boldsymbol{\varepsilon}$ \\
\hline Inlet & $\mathbf{U}=0$ & $\mathbf{V}=0$ & $\mathbf{W}=0$ & $T=T_{\text {jet }}$ & $\left(T_{i} \mathbf{w}_{\text {jet }}\right)^{2}$ & $\left(\mathrm{C}_{\mu} \mathrm{C}_{\mathrm{d}}\right)^{3 / 4}\left(\mathrm{k}^{3 / 2} / \mathrm{L}\right)$ \\
\hline Copper Bl. & $\mathbf{U}=0$ & $\mathbf{V}=0$ & $\mathbf{W}=0$ & $\mathrm{q}^{\prime \prime}=1000 \mathrm{~W} \mathrm{~m}^{-2}$ & $k=0$ & $\partial \varepsilon / \partial \mathrm{x}=0$ \\
\hline Outlet & $\partial \mathbf{U} / \partial \mathrm{x}=0$ & $\partial \mathbf{V} / \partial \mathrm{x}=0$ & $\partial \mathbf{W} / \partial \mathrm{x}=0$ & $\partial T / \partial \mathrm{x}=0$ & $\partial k / \partial \mathrm{x}=0$ & $\partial \varepsilon / \partial \mathrm{x}=0$ \\
\hline Left wall & $\mathbf{U}=0$ & $\mathbf{V}=0$ & $\mathbf{W}=0$ & $\partial T / \partial \mathrm{x}=0$ & - & - \\
\hline Front-back wall & $\mathbf{U}=0$ & $\mathbf{V}=0$ & $\mathbf{W}=0$ & $\partial T / \partial \mathrm{y}=0$ & - & - \\
\hline Top wall & $\mathbf{U}=0$ & $\mathbf{V}=0$ & $\mathbf{W}=0$ & $\partial T / \partial \mathrm{z}=0$ & - & - \\
\hline
\end{tabular}

\section{Results and discussions}

In this section, temperature and velocity measurements and CFD results are presented together to describe the heat transfer and flow field on electronic components in a channel using an impinging jet. Investigations were performed for $\mathrm{Re}=4000-8000$ at $\mathrm{H}=10 \times \mathrm{D}_{\mathrm{h}}$, where $\mathrm{H}$ shows the channel height.

The PIV measurement as well as numerical simulation results are presented in this section. PIV is a measurement technique used to obtain the instantaneous velocity field in a cross section of flow [18]. SAFEX Blitz-Reflex fog fluid was used to seed the flow field in this study. Data were processed by Dynamic Studio V3.31. The data was processed using adaptive correlation and also average correlation schemes. A $16 \times 16$ interrogation area was used with $25 \%$ overlap for the adaptive correlation. The number of refinement steps was set as 3. A POD projection and POD snapshot was taken after the adaptive correlation. For the average correlation a $32 \times 32$ interrogation area was used with $50 \%$ overlap. The average correlation was performed for 200 images and a average filter was used after the scheme.

Figures 5- 7 show velocity fields obtained from PIV measurement results, processed using the adaptive and average correlation schemes. Numerical results are also shown in the figures to make a comparison. Results are presented for $\mathrm{Re}=4000, \mathrm{Re}=6000$ and $\mathrm{Re}=8000$, respectively.

The results obtained from the numerical simulation are shown in Figure 5 (c) for $\mathrm{Re}=4000$. All the velocity vectors were enlarged to observe the impingement and wall jet region as well as to coincide with the PIV interrogation area.

It is observed that the numerical results are in agreement with the PIV measurement results for all Re numbers. For all Re numbers, an air bubble forms at the impingement region and prevents the jet from impinging directly on the surface. Due to this, it is expected that the highest heat transfer will occur around the impingement region. This phenomenon was better observed with increasing Re number and the flow begins to change direction at higher vertical locations. This is attributed to the fact that the pressure over the surface is significantly higher with increasing Re number, and formation of an air bubble prevents the air jet from impinging on the surface. The wall jets with increasing Re number have higher velocities over the electronic components which have an augmenting effect on heat transfer [17]. Also, recirculations increase with increasing Re number, which can be observed from the figures. An increase in the recirculations have an increasing effect on the jet flow structure and entrainment. These have in general a deteriorating effect on heat transfer.

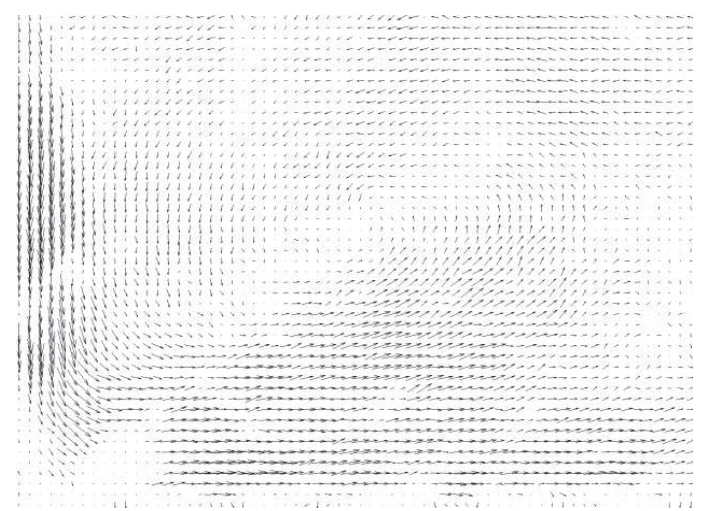

(a) Adaptive correlation results

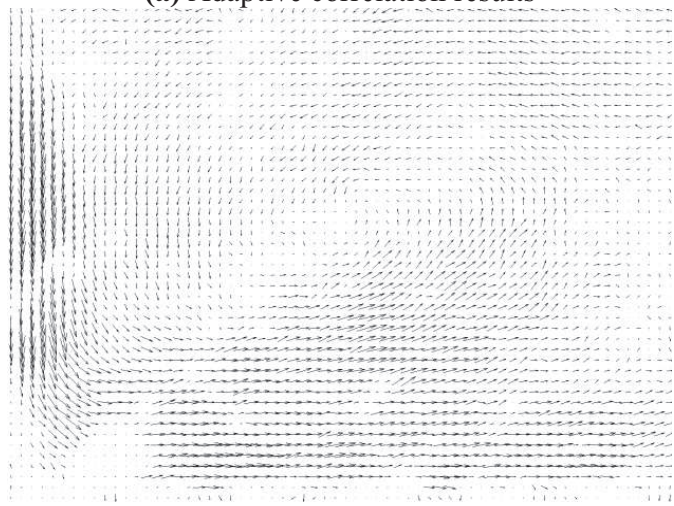

(b) Average correlation results

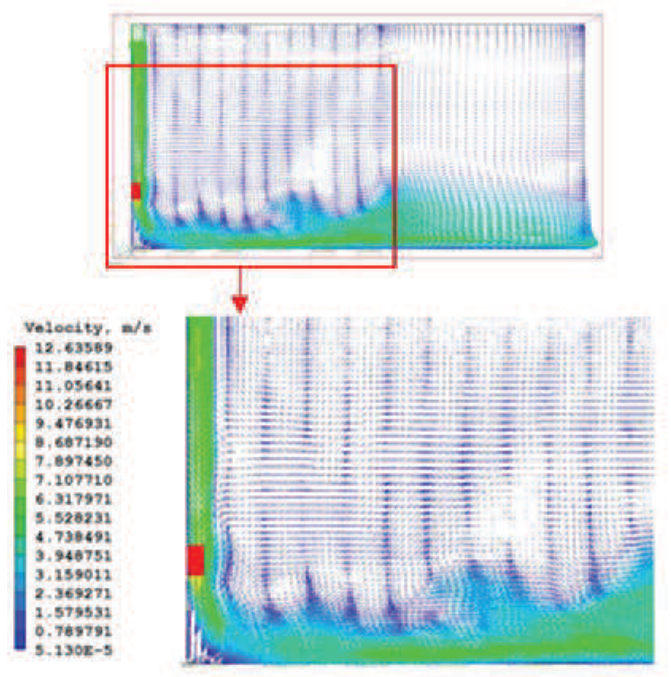

(c) Numerical simulation results

Figure 5. PIV and numerical velocity results for $\mathrm{Re}=4000$ 


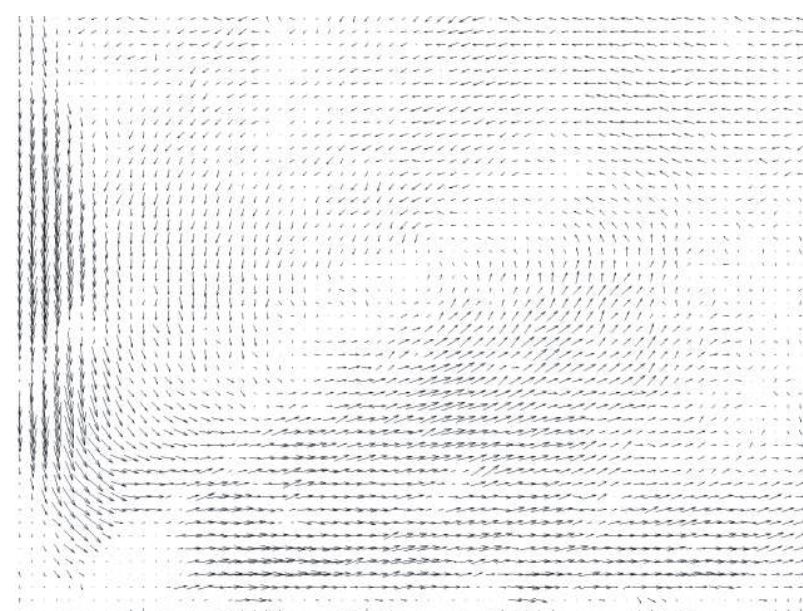

(a) Adaptive correlation results

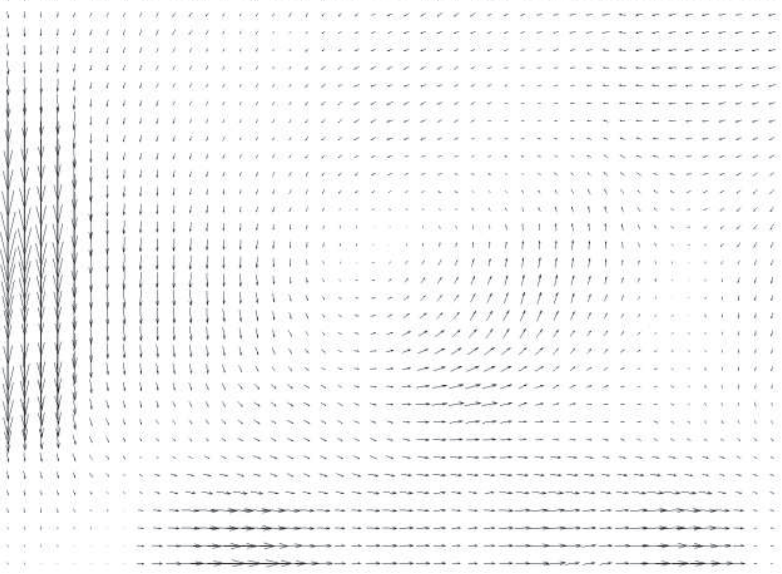

(b) Average correlation results

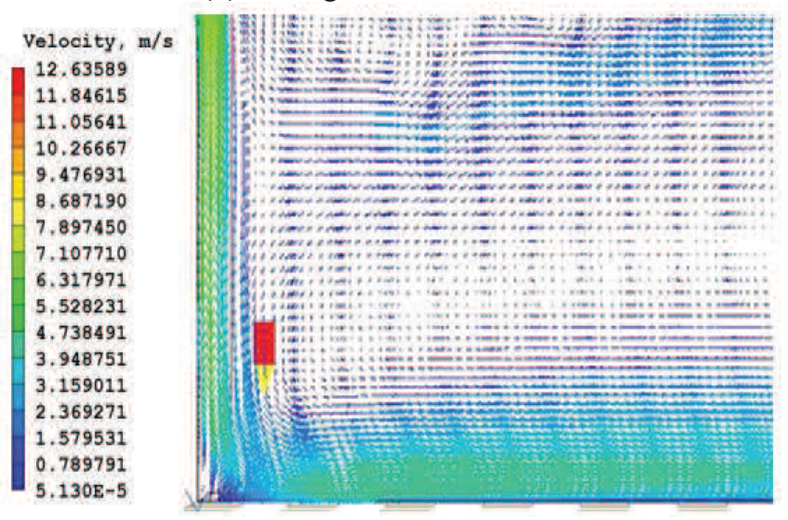

(c) Numerical simulation results

Figure 6. PIV and numerical velocity results for $\mathrm{Re}=6000$

It was also observed that average and adaptive correlation schemes have almost the same results. Especially, for $\mathrm{Re}=4000$ and $\mathrm{Re}=6000$ the results are nearly the same. Although, for $\mathrm{Re}=8000$ the recirculations were better observed for the adaptive correlation, but the results obtained using the average correlation are also reasonable. This shows that the results for both correlation schemes represent the flow field of the impinging jet inside the channel. However, one can see that the correlation schemes can have an effect on the flow field results obtained from PIV measurements, which should be investigated in more detail.

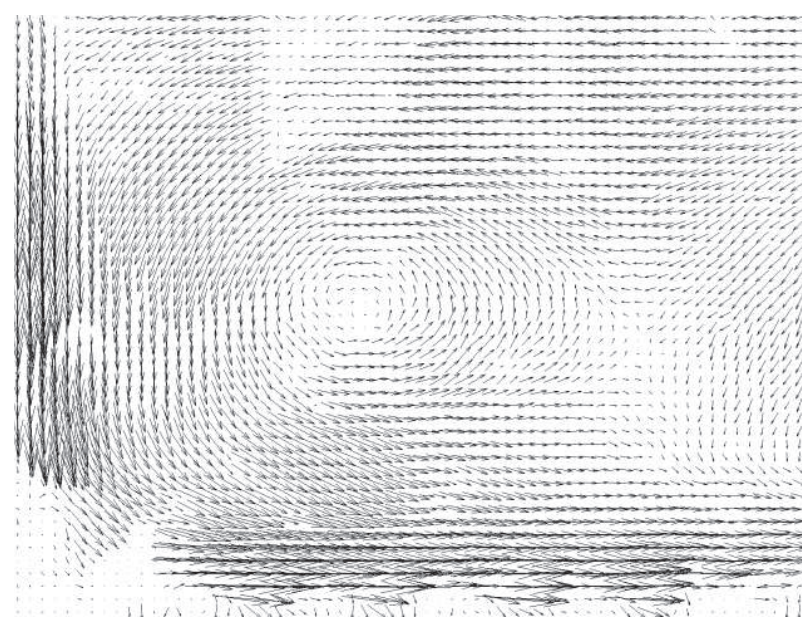

(a) Adaptive correlation results

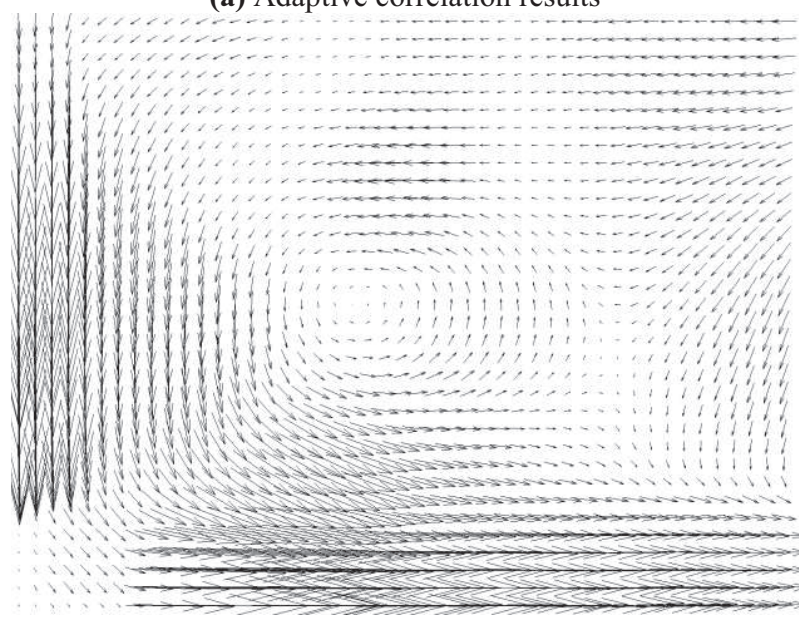

(b) Average correlation results

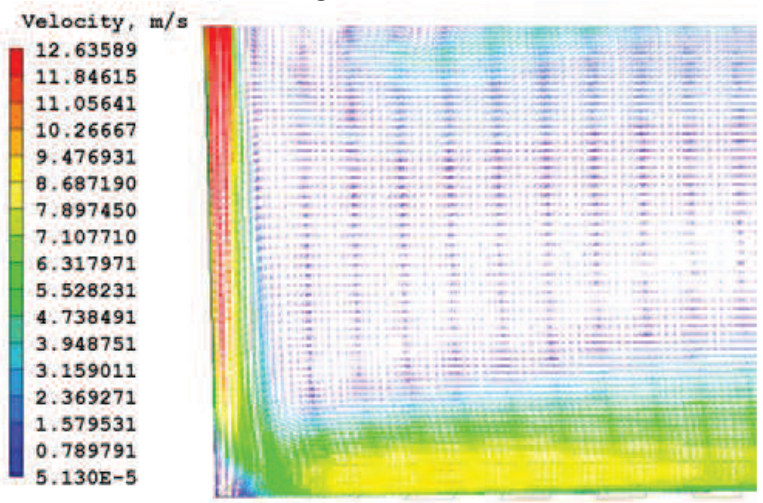

(c) Numerical simulation results

Figure 7. PIV and numerical velocity results for $\mathrm{Re}=8000$

The results obtained from the PIV measurements were presented and the flow field was observed for different Re numbers. These results were used in the interpretation of the heat transfer from copper blocks in a channel using an impinging jet.

After the PIV results the experimental and numerical $\mathrm{Nu}$ number distributions for $\mathrm{Re}=8000$ and $\mathrm{H} / \mathrm{D}_{\mathrm{h}}=10$ are 
shown in Figure 8. The experimental $\mathrm{Nu}$ number values were obtained from the temperature measurements and calculated using Eq. 9. It is observed that the numerical results are in agreement with the experimental results. The highest $\mathrm{Nu}$ number values were obtained for the second row of copper blocks. An increase in heat transfer between the first row and second row reaches its highest value at the $2^{\text {nd }}$ row, and begins to decrease with increasing row number. The reason for this is attributed to the fact observed from the PIV flow field measurements which showed an air bubble that prevents the jet impinging directly on the surface. This corresponds to the region of the first heater row. CFD results show a good agreement and the distribution is compatible with the experimental measurement.

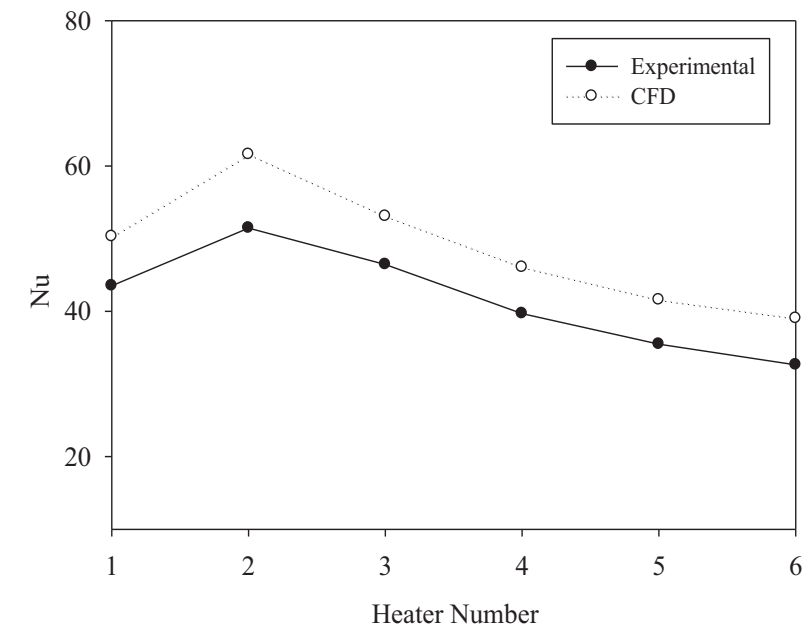

Figure 8. Nu number distribution for $\mathrm{Re}=8000$

\section{Conclusion}

The present study was mainly focused on experimental and numerical investigation of heat transfer and flow from a group of electronic components, inside a rectangular channel, by using a single jet flow. The local Nusselt numbers were achieved for $\mathrm{Re}=4000,6000$ and 8000. PIV measurements were performed to observe the flow field of the impinging jet in the channel with one end open. The data was processed using adaptive correlation and also average correlation schemes. Temperatures at the centers of the 18 ( $3 \times 6$ array) copper blocks, which represent electronic components, were measured using calibrated T-type thermocouples inserted through $2 \mathrm{~mm}$ holes inside the thickness of the blocks. A numerical study was performed and validated with experimental results. Numerical flow field results were obtained and compared with PIV measurement results.

It was observed that for all Re numbers the flow decelerates after the jet outlet and changes its direction near the wall. The flow after impingement changes its direction and starts to accelerate away from the stagnation point. For all Re numbers, an air bubble forms at the impingement region and prevents the jet from impinging directly on the surface. This phenomenon was better observed and the flow begins to change direction at higher vertical locations with increasing Re number. Also recirculations increase with increasing Re number.

The highest $\mathrm{Nu}$ number values were obtained for the second row of copper blocks and begins to decrease with increasing row number.

Numerical flow field results were obtained for $\mathrm{Re}=$ 4000,6000 and 8000. It was observed that the CFD results are in agreement with the measurements.

\section{Acknowledgements}

The financial support of this study by the research fund of TUBITAK under Grant No. 113M331, and the research fund of Gazi University under Grant No. 06/2014-02 is gratefully acknowledged. Also, the financial support of this study by the research fund of Pamukkale University is gratefully acknowledged.

\section{References}

1. A.H. Beitelmal, M.A. Saad, C.D. Patel, Int. J. of Heat and Fluid Flow 21, 156-163 (2000)

2. S.A. Nada, Heat and Mass Transfer 43, 135-148 (2006)

3. L. Cheng-Geng, Z. Jie-Min, Chem. Eng. Tech. 30, 1355-1361 (2007)

4. W.M. Yan, H.C. Liu, C.Y. Soong, W.J. Yang, Int. J. of Heat and Mass Transfer 48, 2420-2428 (2005)

5. K. Choo, S. Kim, Int. J. of Heat and Mass Transfer 53, 3366-3371 (2010)

6. S. Caliskan, Experimental and Numerical Investigation of Heat Transfer from Rib-Roughened Surfaces with Different Impinging Jets, Ph.D. Thesis, (2012)

7. S. Caliskan, Int. J. of Heat and Mass Transfer 66, 244-260 (2013)

8. S. Caliskan, S. Baskaya, Int. J. of Thermal Sciences 59, 234-246 (2012)

9. M.F. Koseoglu, S. Baskaya, Int. J. of Thermal Sciences 49, 1417-1426 (2012)

10. L.F.G. Geers, M.J. Tummers, T.J. Bueninck, K. Hanjalic, Int. J. of Heat and Mass Transfer 51, 53895399 (2008)

11. L.F.G. Geers, M.J. Tummers, K. Hanjalic, Experiments in Fluids 36, 946-958 (2004)

12. R. Jia, M. Rokni, B. Sunden, Int. J. of Numerical Methods for Heat and Fluid Flow 11, 642-662 (2001)

13. D. Rundstrom, B. Moshfegh, Int. J. of Heat and Mass Transfer 28, 1360-1378 (2007)

14. S.J. Wang, A.S. Mujumdar, Applied Thermal Engineering 25, 31-44 (2005)

15. J. Bredberg, L. Davidson, J. of Fluids Engineering, Trans. of the ASME 126, 14-21 (2004)

16. C.P. Koutsou, S.G. Yiantsios, A.J. Karabelas, J. of Membrane Science 231, 81-90 (2004)

17. M. Kilic, Experimental and Numerical Investigation of Convective Heat Transfer from Electronic Components in a Channel by Impinging Jets, Ph.D. Thesis, (2013) 
EPJ Web of Conferences

18. M. Raffel, C.E. Willert, S. Wereley, J. Kompenhans, Particle Image Velocimetry, Springer Press, Berlin, (1998) 